\title{
Black representation matters
}

Imraan Nagdee, MD

Division of Urology, University of Toronto, Toronto, ON, Canada

Cite as: Can Urol Assoc J 2020 June 19; Epub ahead of print. http://dx.doi.org/10.5489/cuaj.6782

Published online June 19, 2020

****

It is well-known that race plays an important role in patient outcomes. As urologists, we see it most clearly in the disproportionate incidence and mortality rates of Black patients with prostate cancer. ${ }^{1}$ A similar, though less obvious story, is seen in bladder, penile, and kidney cancer. ${ }^{1,2}$ Despite these disparities, a recent study found that $96 \%$ of patients enrolled in prostate cancer trials between 1987 and 2016 were white. More alarmingly, there was a decrease in the proportion of Black or African American men enrolled in clinical trials between 1995 and 2014. ${ }^{3}$

Impediments to enrolling Black patients into clinical trials are manifold. A United States systematic review identified five key elements that influence African American participation in oncology clinical trials. ${ }^{4}$ One of these was the role of health care providers in influencing Black patient participation in clinical trials. Studies have shown that patients who are the same race as their physician have longer clinical encounters that result in improved patient satisfaction. ${ }^{5}$ As such, increasing the number of Black physicians to build trust and better represent patient populations is a worthwhile endeavour.

While the Black population in Canada is significantly smaller than that of the United States, Canada's Black population has doubled between 1996 and 2016, and it continues to grow. ${ }^{6}$ As the population ages it should come as no surprise if we see a growing number of Black patients succumb to urologic conditions at disproportionate rates compared to their non-Black counterparts. It is our responsibility as urologists to be proactive in creating opportunities for Black trainees and future colleagues who will be well-suited to help address this head on.

Recent events, including the deaths of George Floyd in Minnesota and Regis KorchinskiPaquet in Toronto, have once again brought anti-blackness and systemic racism into the public eye. Health care, its institutions, and we as members of them, are not immune to these longstanding societal ills. The urology community in Canada should use this as an opportunity to take stock of where it stands with respect to Black representation in our field. At present, our shortcomings are telling. As of June 2020, there is one Black urology resident across all levels of 
training within thirteen Canadian programs. This lack of representation exists amongst consultant urologists as well.

There is, however, reason to be optimistic. At the University of Toronto, twenty-four Black medical students have been accepted into the class of 2024, making this the largest cohort of Black medical students in Canadian history. ${ }^{7}$ Furthermore, Black medical students are now enrolled across all seventeen medical schools in Canada. Urology training programs across the country should make it a priority to promote their programs to this group of learners as they will undoubtedly become assets to the field and to their future patients.

Increasing the number of Black urology trainees is only part of the solution. With a limited number of Black faculty members, there exists a void of racially concordant role models for students and residents. Nonetheless, an earnest mentor of any race can become a strong ally, if within a non-discriminatory environment that fosters academic advancement and professional promotion. Without this, efforts to maintain diversity will continue to fall short. Our patients will lose young and intelligent students that choose paths other than urology because they lack representation or mentorship. These efforts require strong but humble leadership that recognizes individual and collective biases, while creating policies that prevent the perpetuation of racebased barriers that have existed for far too long.

We exist on a spectrum of privilege. It is incumbent on each and every one of us to recognize that privilege, reflect on it, and use it to level the playing field for future urologists. It cannot continue to fall upon the shoulders of our Black colleagues to dismantle the systems that have kept them from joining us in our common cause. We owe it to those colleagues and to our patients to be the ones to bear that burden.

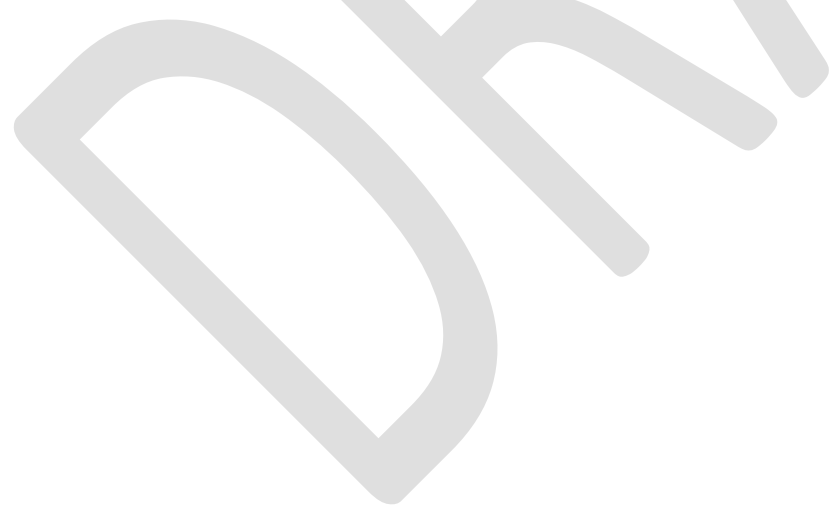




\section{References}

1. Das H, Rodriguez R. Health care disparities in urologic oncology: A systematic review. Urology 2020;136:9-18. https://doi.org/10.1016/j.urology.2019.09.058

2. Rippentrop JM, Joslyn SA, Konety BR. Squamous cell carcinoma. Cancer 2004;10:135763. https://doi.org/10.1002/cncr.20519

3. Rencsok EM, Bazzi LA, McKay RA, et al. Diversity of enrollment in prostate cancer clinical trials: Current status and future directions. Cancer Epidemiol Biomarkers Prev 2020. [Epub ahead of print]. https://doi.org/10.1158/1055-9965.EPI-19-1616

4. Rivers D, August EM, Sehovic I, et al. A systematic review of the factors influencing African Americans' participation in cancer clinical trials. Contemp Clin Trials 2013;35:13-32. https://doi.org/10.1016/j.cct.2013.03.007

5. Shen MJ, Peterson EB, Costaz-Mũniz R et al. The effects of race and racial concordance on patient-physician communication: A systematic review of the literature. J Racial Ethn Health Disparities 2018;5:117-40. https://doi.org/10.1007/s40615-017-0350-4

6. Statistics Canada. Diversity of the Black population in Canada: An overview [Internet]. [updated 2019 February 27; cited 2020 July 12]. Available at:

7. https://www150.statcan.gc.ca/n1/pub/89-657-x/89-657-x2019002-eng.htm Accessed July $10,2020$.

8. University of Toronto. $\mathrm{U}$ of $\mathrm{T}$ expresses solidarity with the Black community [Internet]. [updated 2020 June 2; cited 2020 July 12]. Available at: https://www.utoronto.ca/news/ut-expresses-solidarity-black-community. Accessed July 10, 2020. 